\title{
THE STUDY ON EFFECTS OF WALKING ON THE THERMAL PROPERTIES OF CLOTHING AND SUBJECTIVE COMFORT
}

\author{
Ivana Špelić*, Dubravko Rogale and Alka Mihelić Bogdanić \\ University of Zagreb Faculty of Textile Technology, Zagreb, Croatia \\ *E-mail: spelic@ttf.hr
}

\begin{abstract}
:
Former studies done by other authors investigated the first- and second-layered air gaps beneath the clothing garments. None of the previous studies reported multidisciplinary clothing design testing approach linking both the objective measuring methods and subjective responses, while testing the thermal properties linked to a microclimatic volume formed between the layers of garments forming the ensemble. Neither was determined the limiting value of the microclimatic volume for outerwear garments, after which the thermal insulation will start to decrease due to convection. By taking the advantage of the precise three-dimensional (3D) body scanning technology and reverse engineering $3 D C A D$ tool, the volume of the microclimatic air layers formed under outerwear garments was determined to study the impact of the ensemble's microclimatic volume on the overall insulation value, measured by means of the thermal manikin. The jacket with the smaller microclimatic volume provided $5.2-13.5 \%$ less insulation than wider jackets, while the ensembles with tighter jackets showed 0.74-1.9\% less insulation in static and 0.9$2.7 \%$ more insulation in dynamic conditions, thus proving that the limiting value of the microclimatic volume is greater than previously reported for three-layered ensembles. The effective thermal insulation value was reduced in average by $20.98-25.34 \%$ between standing and moving manikins. The thermal manikins are designed for steadystate measurements and do not work well under transient conditions, so three human subjects were employed as evaluators of the clothing thermal quality. In cooler climatic conditions, the measured physiological parameters and subjects' grades pointed to discomfort while wearing ensembles with tighter jackets.
\end{abstract}

\section{Keywords:}

air gap volume, 3D CAD volume quantification, reverse engineering analysis, dynamic insulation changes, subjective comfort evaluation

\section{Introduction}

The study on the effects of walking on the thermal properties of clothing and subjective comfort requires multidisciplinary testing approach, but so far only a negligible number of studies have tried to link the limiting value of the microclimatic volume for outerwear garments, after which the thermal insulation will start to decrease due to convection. Garments create a certain microclimate around the body, [1, 2] affecting the thermal comfort felt by humans [3]. The average microclimatic air layer thickness plays an important role in the heat transfer between the body and the environment, especially when considering the trapped, still air in steady state [1,4-6]. A small change by $5 \mathrm{~mm}$ in the air gap thickness will noticeably increase both thermal and evaporative resistances of the garment in the steady-state conditions [7, 8]. However, after exceeding a certain limiting volume or thickness, the air becomes an ineffective insulator $[9,10]$ as increased convective airflow potential enhances the inhomogeneous heat and mass transfer in clothing [6-8]. The body motion and wind will further increase the potential for heat transfer [11-15] while forcing the convection, which prevents the linear increase of total dry heat loss [6, 16-21]. The standardized methods for measuring thermal insulation of clothing tend to neglect the local air gap thickness, the contact area, and the spatial variations due to body shape, posture, movement, and clothing draping $[6-8,15]$.

By selecting the appropriate fabric type and the design of ease allowances, one can adjust the garment's comfort level [22] since the additional air spaces formed under outerwear garments appear to dominate the overall thermal properties of clothing ensembles [23]. Former studies investigated only the microclimatic air layers formed under first- and second-layer ensembles [4, 9, 20, 22, 24-28]. Previously, the decrease in thermal insulation was reported when the air gap volume was greater than 6 [24] and $11.9 \mathrm{dm}^{3}$ [27].

Since the three-dimensional (3D) scanning is currently the most reproducible and precise method for quantifying the air volume formed under clothing [4], in this study, the volume was determined by 3D scanner and calculated by the reverse engineering $C A D$ suite Geomagic. The method for the quantification of the microclimatic volume is adopted from the study by Psikuta et al. [15, 25], differing in the overall volume quantification under third microclimatic layer scanning three male subjects. The determination of air gap thickness is usually done on stationary manikins using advanced 3D scanning and post-processing methods, since processing $3 D$ data of moving 
human body is still in its infancy. It requires the same postprocessing procedure to get the 3D animation even when using multiple high-quality $3 \mathrm{D}$ scanners to capture all sides of the moving object and temporal-3dMD systems [29].

Although few started investigating the triple-layer composite arrangements for reducing thermal burden [6, 30], studies covering the three-layered ensembles with outerwear garments are rarely reported. This study investigates the impact of the walking on the decrease of thermal insulation in accordance with the volume of the air trapped inside the clothing microclimate formed under the outerwear layers (three-layered ensembles) and afterward the comfort state of subjects.

\section{Materials and test methods}

The objective testing methods were covered in the first part of the experimental study. This involved the material testing, the jacket construction, the 3D scanning, the scan preparation, and the thermal manikin testing. Previous studies on the microclimatic volume affecting the clothing insulations were mostly obtained with manikin stationary $[9,20,27,28,31]$. However, since the ventilation when walking forces the insulation reduction ([12, 32-36]), the multidisciplinary approach with moving thermal manikin was used.

The second part of the experimental study covered the wear trials with the subjective judgments expressed by the human subjects and simultaneous evaluation of physiological parameters. The human subjects, dressed into selected ensembles, were scanned in the 3D scanner. After scan postprocessing, the clothing's area and the volume were computed. Since Psikuta et al. [25] proved the low variability of the air gap thickness and such variability leading to less than $1 \%$ change in the thermal resistance of the air gap beneath the garment, only the overall volume of microclimatic air layer was measured.

In this study, the impact of the microclimatic air volume on the overall insulation value was tested under dynamic condition in order to fully understand the impact of the air currents and ventilation of the air inside the clothing microclimate on the insulation decrease due to the corresponding bellows effect set to motion during walking.

\subsection{Objective measuring methods}

\subsubsection{Material testing and clothing selection}

The three-layered laminate was used to produce the outer shell. It consisted of the $100 \%$ polyester (PES) as outer layer and inner lining and the middle layer was polytetrafluorethylene (PTFE) membrane protected with polyurethane (PU) particles. The $100 \%$ PES fabric was used as lining, while the underlying garments were composed of $100 \%$ cotton (such as jeans trousers and shirts) and produced in size 50.

The material testing was performed as follows:

- Mass per unit area according to ISO 3801 [37]

- $\quad$ Thickness (h) according to ISO 5084 [38]

- $\quad$ Air permeability (AP) according to ISO 9237 [39]

- Water vapor resistance $\left(R_{\mathrm{et}}\right)$ and thermal resistance $\left(\mathrm{R}_{\mathrm{ct}}\right)$ according to ISO 11092 at relative humidity $(\mathrm{RH})=60 \%$ (1993) [40].

Table 1 summarizes the structural and physical characteristics of the materials used to produce the selected garments [41].

The underwear composed of $100 \%$ cotton was used to provide good moisture wicking with minimal heat retention in mild-tocool ambient conditions in order to avoid eventual discomfort during wear trials since the cotton fibers are breathable and absorbent and thus provide feeling of comfort while wearing such fabrics in close contact with body [42, 43]. The jackets as outerwear garments have greater values of the ease allowances added and correspondingly provide greater microclimatic volume, which will foster an increase in forced convection. Thus, the four variants of the male bomber jacket were constructed by CAD Lectra Systemes and produced from the same materials, differing from one to another in the amount of the ease allowance added strictly to the chest $(100 \mathrm{~cm})$ and the waist circumference $(82 \mathrm{~cm})$ as proposed by Amirova and Sakulina [44], leaving all the other dimensions unaffected (the shoulder seam, the neck opening, the hip circumference, the length of the sleeves, and the length of the jacket; Table 2). Large ease allowances were added according to studies by Moll and Wright [45], who deduced the maximum value of chest expansion while breathing of $11.8 \mathrm{~cm}$ for males aged 2534 years, and Myers-McDevitt [46], who stated that more than

Table 1. Structural and physical characteristics of materials selected for jacket production and garments [41]

\begin{tabular}{|c|c|c|c|c|c|}
\hline Selected materials & $\begin{array}{c}\text { Mass per unit } \\
\text { area }\left(\mathbf{g} / \mathbf{m}^{2}\right)\end{array}$ & $\begin{array}{c}\mathbf{H} \\
\mathbf{( \mathbf { m m } )}\end{array}$ & $\begin{array}{c}\mathbf{A P} \\
\left(\mathbf{l} / \mathbf{m}^{2} \mathbf{s}\right)\end{array}$ & $\begin{array}{c}\mathbf{R}_{\text {et }} \\
\left(\mathbf{m}^{2} \mathbf{P a} / \mathbf{W}\right)\end{array}$ & 9.3767 \\
\hline $\begin{array}{c}\text { Jacket outer fabric being a three- } \\
\text { layer laminate in twill weave }\end{array}$ & 189.20 & 0.3800 & 0 & 0.0706 \\
\hline Jacket lining in plain weave & 54.58 & 0.0776 & 121.4 & 10.0148 & 0.0677 \\
\hline Knitted fabric for undershirts & 157.14 & 0.8636 & 1895.2 & 8.6573 & 0.1151 \\
\hline Knitted fabric for underpants & 134.19 & 0.7347 & 1121.2 & 7.9647 & 0.1124 \\
\hline Fabric for shirts in plain weave & 121.28 & 0.4557 & 331.8 & 7.3747 & 0.0839 \\
\hline Jeans fabric in twill weave & 425.62 & 1.1287 & 48.4 & 11.1716 & 0.0985 \\
\hline
\end{tabular}


$20.32 \mathrm{~cm}$ of ease should be added to chest circumference for loose-fitting garment. The jackets' chest circumference varied from 122 to $126 \mathrm{~cm}$, while waist circumference varied from 118 to $134 \mathrm{~cm}[41]$.

The abbreviation used in the paper to describe jacket variant is CG, while the abbreviation for entire clothing ensemble is CE.

The area of the lower part of the sleeve changed according to the slight changes in the depth of the armhole, following the extension of the chest girth. The area of each pattern part was calculated using the 2D/3D Optitex software. Between jacket variant $C G 1$ and $C G 2$, the increase in the ease allowance was $18.2 \%$. The increase in the ease allowance between jackets CG 2 and CG 3 was $30.8 \%$ and between CG 3 and CG 4 the ease allowance value increased by $11.7 \%$. The initial area calculation of each pattern part was shown in order to compare the results with Geomagic Verify calculations on whole garments.

The above-described garments (undershirt, underpants, shirt, jeans, socks) and jackets formed the testing ensembles, where the ensembles varied only in the jacket variant added. The clothing ensemble CE 0 is the control ensemble without the jacket added to the combination. The ensemble CE 1 had jacket variant CG 1 added, ensemble CE 2 had jacket variant CG 2 added, ensemble CE 3 had jacket CG 3 added, and ensemble CE 4 had CG 4 jacket added.

\subsubsection{The $3 D$ quantification of the microclimatic volume}

The procedure of the quantification of the microclimatic volume, formed between the layers of garments, initially started by the 3D laser body scanning the human subjects. The scanner used is Vitus Smart (Human Solutions $\mathrm{GmbH}$ ). First, the subjects were scanned in a tight underwear in order to quantify the initial volume of the human body. Afterward, the scanning of subjects dressed in the selected clothing ensembles in an upright standing position was conducted. The latter step was performed in order to quantify the overall volume of each selected clothing ensemble.

Since the scanning technology enables the polygonal mesh generation thus reducing the point cloud data without compromising the surface quality, the rendering and determination of volume and surface area can be obtained [47]. The scanned human subjects were imported by the Geomagic Design $X$ software in the obj. format, and the multiple scans were simultaneously processed, aligned, combined into a single fused mesh, and finally reconstructed manually through stages to restore many of the surface features of the clothing complicated geometry. The Geomagic Design X software is used as a powerful 3D CAD tool for the scan modeling, design, engineering, and preparation for the manufacturing.

The stages of the manual scan processing involve healing defects, reconstruction of the mesh features using the remaining polygons, re-meshing and rewrapping, and finally the surface smoothing. After the scans have been edited and processed manually, they are finished by the mesh buildup wizard option and exported to the Geomagic Verify to calculate the volume and the area.

\subsubsection{Thermal insulation measurements}

The dry heat loss was measured performing the manikin test at the constant skin temperature $[9,19,28,33,36,48]$.

The official international standard applied during thermal manikin measurements proposes specific climatic conditions inside climatic chamber and measuring protocol [49]. Since, the air temperature should be set at $12^{\circ}$ below the manikin's mean surface temperature, the ambient air temperature inside the climatic chamber was set to $t_{a}=20 \pm 0.2^{\circ} \mathrm{C}$ with the spatial variations not exceeding $\pm 1^{\circ}$. The $\mathrm{RH}$ was set to $30-70 \%$ with the spatial variations not exceeding $\pm 10 \%$, and the air speed was set to $v_{a}=0.4 \pm 0.1 \mathrm{~m} / \mathrm{s}$ with the spatial variations not exceeding $\pm 50 \%$ of the mean value within $0.5 \mathrm{~m}$ of the manikin

Table 2. Values of the chest circumference, the waist circumference, and the area of pattern parts of the produced male bomber jackets [41]

\begin{tabular}{|c|c|c|c|c|}
\hline Measurement designation & \multicolumn{4}{|c|}{ Dimensions (cm) } \\
\hline Jacket variant & CG 1 & CG 2 & CG 3 & CG 4 \\
\hline Chest circumference $(\mathrm{cm})$ & 122 & 126 & 134 & 138 \\
\hline Ease allowance value added to chest circumference $(\mathrm{cm})$ & 22 & 26 & 34 & 38 \\
\hline Waist circumference (cm) & 118 & 122 & 130 & 134 \\
\hline Ease allowance value added to waist circumference $(\mathrm{cm})$ & 36 & 40 & 48 & 52 \\
\hline Pattern part & \multicolumn{4}{|c|}{ Area $\left(\mathrm{cm}^{2}\right)$} \\
\hline Back & 3410 & 3463 & 3563 & 3619 \\
\hline Lower part of the sleeve & 874 & 874 & 953 & 991 \\
\hline Upper part of the sleeve & 1428 & 1428 & 1428 & 1428 \\
\hline Front & 1419 & 1444 & 1494 & 1523 \\
\hline Total area of the jacket $(\mathrm{cm} 2)$ & 10852 & 10955 & 11313 & 11503 \\
\hline
\end{tabular}


surface. The system should always reach the steady-state conditions and constant values before the testing.

The walk of the thermal manikin simulates the usual human walking rate with the arms and the legs moving in a counter phase under the walking speed of $0.95 \mathrm{~m} / \mathrm{s}$ (corresponds to $45 \pm$ 2 double steps/arm movements per minute). At the beginning of each manikin trial, the nude manikin test was conducted to test the resistance of the air layer. After the jackets' insulation was determined in static conditions, the ensembles' insulation was measured in both static and dynamic conditions. The dynamic conditions refer to the thermal manikin moving, while the static conditions refer to the thermal manikin stationary. The duration of a single thermal manikin measurement was 20 minutes, providing 240 single values in order to automatically calculate the average values of the effective thermal insulation.

According to ISO 15831 [49], the thermal insulation values can be expressed as the effective and total thermal insulation in the static and dynamic conditions. The $I_{c l u}$ is the jackets' effective thermal insulation, $I_{t}$ is the total jacket's thermal insulation value, and $I_{\text {cle }}$ is the effective thermal insulation of the ensemble, acquired by the resting thermal manikin. $I_{\text {cler }}$ is the effective thermal insulation of the ensemble, and $I_{t r}$ is the total thermal insulation of the ensemble, acquired by the thermal manikin moving [49].

\subsection{Wear trials: subjective judgments and physiological data}

The thermal manikin imitates an adult male with the height of $185 \mathrm{~cm}$ and chest girth of $100 \mathrm{~cm}$, and correspondingly three male subjects of resembling body proportions were scanned and laboratory trials were performed. The subjects of the same age (23 years), with the height of $184 \mathrm{~cm}$, chest girth ranging from 98 to $102 \mathrm{~cm}$, and body mass varying from 77 to $79 \mathrm{~kg}$, were scanned in compliance to ISO $13402-3$ [50] and ISO/TR 10652 [51]. Since thermal manikins are designed for steadystate measurements, they do not work well under transient environmental conditions [52] and the human subjects were employed as evaluators of the clothing thermal quality during short-term test trials [53]. Simultaneously, the skin temperature and $\mathrm{RH}$ were measured for Li's study during environmental transients, pointed to the relation between the comfort perception to the skin temperature and microclimatic $\mathrm{RH}$ [54].

After scanning, the same subjects conducted a series of the laboratory trials according to ISO 10551 [55]. The subjects did one trial at the time in specific set of conditions throughout all three phases and were exposed to three sets of the climatic conditions to better correspond to the real conditions of wearing selected garments in the different cool and the moderate workplace environments.

The wear trials are important in order to define a range of ambient temperatures in which clothing can be worn. The basic intention of the produced jackets is to give the appropriate thermal protection under cool environments. The clothing's effective thermal insulation $\left(I_{\text {cle }}\right)$ is required to have a minimum value of $0.190 \mathrm{~m}^{2} / \mathrm{KW}$ and resultant effective thermal insulation $\left(I_{\text {cler }}\right)$ of $0.170 \mathrm{~m}^{2} \mathrm{~K} / \mathrm{W}$ in order to protect against cool environments [56], with ambient temperatures $-5^{\circ} \mathrm{C}<$ ta $<$ $15^{\circ} \mathrm{C}$ [57]. The three sets of the climatic conditions varied in the value of the air temperature $\left(t_{a}\right)$, while the $\mathrm{RH}=50 \%$ and the air speed $\left(v_{a}=1.2 \mathrm{~m} / \mathrm{s}\right)$ remained the same. In the climatic condition A, air temperature was set to $20^{\circ} \mathrm{C}$ (in order to test the thermal comfort felt by humans in warmer environments and to compare the results to the standardized values of the climatic conditions during the thermal manikin testing), in $\mathrm{B}$ it was set to $15^{\circ} \mathrm{C}$, and in $\mathrm{C}$ to $10^{\circ} \mathrm{C}$ (in order to simulate the cool environments).

The wind speed of $1.2 \mathrm{~m} / \mathrm{s}$ was chosen since Havenith et al. [12] proved that the windup to $4 \mathrm{~m} / \mathrm{s}$ has a small effect on the intrinsic clothing insulation, because it does not penetrate materials and thus does not disturb the entrapped air layers.

In this study, different activities (walking and resting) and ensembles (CE 2 to CE 5) were combined to examine the insulation values and the subjective judgments. During each laboratory trial, which lasted for altogether for 70 minutes and was divided into three phases, the questionnaires were filled thrice, at the end of each trial phase, under artificially designed ambient conditions (A, B, or C) in the computer-controlled climatic chamber (Figure 1).

The cold exposure starts with a cooling period of 20-40 minutes, since the heat content of the body tissues is reduced, particularly

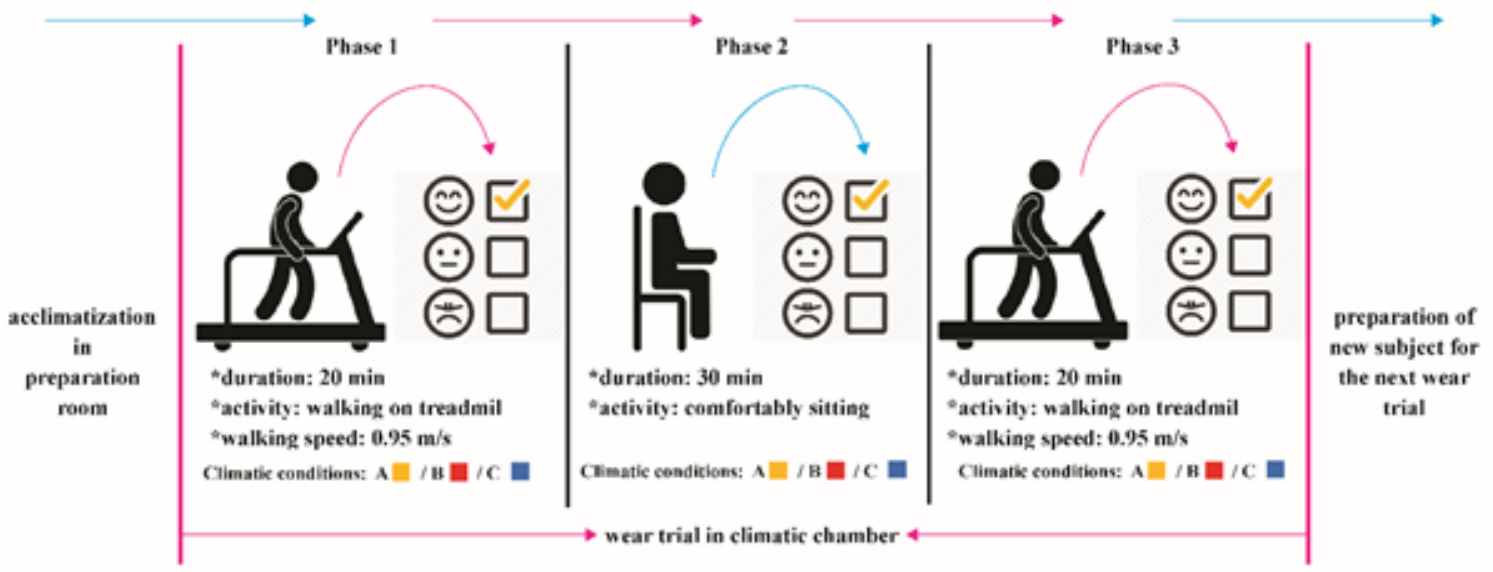

Figure 1. Phases of wear trials 
the skin and the extremities. For the calculation of the heat balance and for some comparisons between conditions and the heart rate were averaged over 10 and 20 minutes during the subjective ratings. The purpose of the selected time interval for averaging was to describe the most constant phases of each experiment and to reduce the effects of small variations during the period [58]. The thermal equilibrium is then restored for the values of the mean skin temperature.

Special questionnaire was developed, and the subjects were asked to fill it during trials. The objective of the questionnaire was to determine the influence of the thermal environment and the clothing on the overall thermal state of the subjects in the transient conditions. The answers to the questions were given in the form of the evaluative judgment scale which is one pole scale consisting of $5^{\circ}$, where 0 stands for point of origin and 1 , 2,3 , and 4 are degrees describing intensity. Grade 0 was taken as the complete comfort and corresponds to the satisfaction of $100 \%$, while grade 4 corresponds to $0 \%$ of satisfaction or a complete lack of comfort felt by the subject. The grades have only positive values.

The physiological parameters have been measured simultaneously. The physiological reactions during wear trials can be objectively measured as a change of the physiological parameters or perceived subjectively, based on the assessment of the thermal comfort using the subjective judgment scales [55].

In order to validate the evaporation of the sweat from the surface of the skin, a body mass loss $\left(\Delta \mathrm{m}_{\mathrm{sw}}\right)$ due to sweating was calculated according to ISO 9886 [59]:

$$
\Delta \mathrm{m}_{\mathrm{sw}}=\Delta \mathrm{m}_{\mathrm{g}}-\left(\Delta \mathrm{m}_{\mathrm{res}}+\Delta \mathrm{m}_{\mathrm{o}}+\Delta \mathrm{m}_{\text {wat }}+\Delta \mathrm{m}_{\mathrm{sol}}+\Delta \mathrm{m}_{\mathrm{clo}}\right)(\mathrm{kg})(1),
$$

where $\Delta \mathrm{m}_{\mathrm{g}}$ is the gross body mass loss $(\mathrm{kg}), \Delta \mathrm{m}_{\mathrm{sw}}$ is the body mass loss due to sweat loss during the time interval $(\mathrm{kg}), \Delta \mathrm{m}_{\text {res }}$ is the body mass loss due to evaporation in the respiratory tract $(\mathrm{kg}), \Delta \mathrm{m}_{\mathrm{o}}$ is the mass loss due to the mass difference between carbon dioxide and oxygen $(\mathrm{kg}), \Delta \mathrm{m}_{\text {wat }}$ is the mass variation of the body due to intake and excretions of water $(\mathrm{kg}), \Delta \mathrm{m}_{\mathrm{so}}$ is the mass variation of the body due to intake and excretions of solids $(\mathrm{kg}), \Delta \mathrm{m}_{\mathrm{clo}}$ is the mass variation due to variation of clothing or sweat accumulation in the clothing $(\mathrm{kg})$.

The evaluation of the thermal strain due to sweat loss was calculated as an amount of sweat evaporated from the body and condensed into the clothing. The overall amount of sweat excreted was calculated from the difference in the gross body mass of the test subjects $\left(\Delta \mathrm{m}_{\mathrm{g}}\right)$, the mass variation due to variation of clothing or to sweat accumulation in the clothing $\left(\Delta \mathrm{m}_{\mathrm{clo}}\right)$, and the amount of sweat evaporated to the environment. The electronic scale TPT3 (Libela, Celje) with the accuracy of $\pm 2 \mathrm{~g}$ was used to measure the garment's weight, and the electromechanical scale E 2100/5 (Libela, Celje) with accuracy of $\pm 5 \mathrm{~g}$ was used to measure the subject's weight. Since there was no intake of fluids or food and no excretions of urine or solids, the mass variation of the body due to intake and excretions of water $\left(\Delta \mathrm{m}_{\text {wat }}\right)$ and the mass variation of the body due to intake and excretions of solids $\left(\Delta \mathrm{m}_{\mathrm{sol}}\right)$ were equal to 0 . The body mass loss due to evaporation in the respiratory tract $\left(\Delta \mathrm{m}_{\text {res }}\right)$ and the mass loss due to the mass difference between carbon dioxide and oxygen $\left(\Delta \mathrm{m}_{\mathrm{o}}\right)$ were calculated on the basis of the average metabolic rate $\left(M=115 \mathrm{~W} / \mathrm{m}^{2}\right.$ under walking phase and $60 \mathrm{~W} / \mathrm{m}^{2}$ under resting phase) [60], the respiratory quotient $(R=0.80)$, and the DuBois and DuBois body area $\left(2.029 \mathrm{~m}^{2}\right)$ [61].

The measurement of body temperature is another important parameter to determine the thermal state of the human body [62] but implies the maintenance of body temperature within relatively narrow limits [63]. When the mean skin temperature falls below $31^{\circ} \mathrm{C}$, discomfort occurs as the effect of cooling in the cold [64]. Another study by Liz et al. concluded even higher values of the mean skin temperature of resting person who feels thermal comfort. The mean skin temperature of $32.6^{\circ} \mathrm{C}$ is the limit between cool discomfort and comfort, and $33.7^{\circ} \mathrm{C}$ is the limit between comfort and warm discomfort [65].

The mean skin and the skin's RH were deduced by a modular signal recorder MSR 12 (MSR Electronics GmbH, Switzerland). The average or the mean skin temperature $\left(t_{\mathrm{sk}}\right)$ was measured at the skin's surface with 8 external digital waterproof temperature sensors encased in an epoxy (the working range -40 to $125^{\circ} \mathrm{C}$, the resolution $0.0625^{\circ} \mathrm{C}$, the accuracy $\pm 0.5^{\circ} \mathrm{C}$ at -10 to $85^{\circ} \mathrm{C}$ ). Although accurate measurement of the body temperature with temperature sensors encased in an epoxy is less precise [66], noninvasive measuring methods were used. The accumulation of moisture to clothing was measured during trials by weighting clothing before and after trials, since during activities human body starts sweating. The evaporated sweat penetrates the fabric [67] in close contact with the skin and can cause the subjects to feel uncomfortable [68].

The mean skin temperature is the mean value of the skin over the whole body according to ISO 9886 [59], and the weighting scheme according to 8 measuring points was selected. It was calculated by weighting each of the local temperatures with the coefficients corresponding to the relative surface of the body area that each measuring point represented [59]:

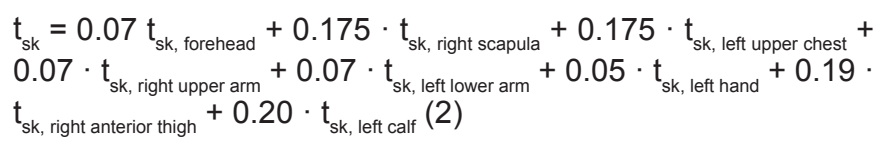

\subsection{Statistical analysis}

The statistical analysis was performed using MS Excel and the statistical software STATISTICA. The average mean skin's temperature $\left(\mathrm{t}_{\mathrm{sk}}\left[{ }^{\circ} \mathrm{C}\right]\right)$ and the average skin's $\mathrm{RH}\left(\mathrm{RH}_{\mathrm{sk}}\right.$ [\%]) between different climatic conditions and for the selected clothing ensembles were calculated.

The statistical analysis of each scale was assigned by the standard ISO 10551 [55]. Since this is the preliminary research of the volume impact on the insulation of the three-layered clothing, only three subjects were chosen to perform wear trials. 
The percentage of judgments expressing discomfort was calculated for the answered questions. The values have been converted to the percentage and analyzed. Since Li's study [24] pointed to the relation between the comfort perception to skin a temperature and microclimatic $\mathrm{RH}$ during environmental transients, the multiple regression analysis was performed.

The correlation was performed between the percentage of judgments expressing discomfort and the thermal state.

The multiple regression analysis was performed to analyze the connection between the percentage of judgments expressing discomfort $\left(\mathrm{D}_{\mathrm{ex}}[\%]\right)$, the mean skin temperature (tsk $\left.\left[{ }^{\circ} \mathrm{C}\right]\right)$ and skin's $\left(\mathrm{RH}_{\mathrm{sk}}[\%]\right)$. The similar analysis was done to compare the mutual influence of the ensemble's microclimatic volume $\left(V_{\mathrm{ml}}\left[\mathrm{dm}^{3}\right]\right)$ on the effective thermal insulation of clothing ensemble in static conditions $\left(I_{\text {cle }}\left[\mathrm{m}^{2} \mathrm{~K} / \mathrm{W}\right]\right)$ or in dynamic conditions $\left(I_{\text {cler }}\left[\mathrm{m}^{2} \mathrm{~K} / \mathrm{W}\right]\right)$ and the percentage of judgments expressing discomfort $\left(\mathrm{D}_{\mathrm{ex}}[\%]\right)$.

\section{Results and discussion}

\subsection{Volume calculations and their impact on the effective thermal insulation values}

The Geomagic Verify Viewer software following the scan reconstruction calculated the volumes and the surface areas of the naked body and the clothed body. As summarized in Table 3 , the volume $\left(\mathrm{V}_{\mathrm{CE}}\right)$ and the area $\left(\mathrm{A}_{\mathrm{CE}}\right)$ of the selected clothing ensembles were calculated initially, and later the increase in the ease allowance value in comparison to jacket CG 1 was calculated, while Table 4 summarizes the volume of the microclimatic air layer under the selected clothing ensembles $\left(\mathrm{V}_{\mathrm{ML}, \mathrm{CE}}\right)$ and jackets $\left(\mathrm{V}_{\mathrm{ML}, \mathrm{CG}}\right)$. The average $(\overline{\mathrm{X}})$ and standard deviation $(\sigma)$ values are summarized in Tables 3 and 4 as calculated by previous study [31].
As summarized in Table 3, the average overall ensemble volume is much bigger than previously reported [4, 69, 70], but do roughly correspond to study done by McQuerry et al. [71], although this study was done on three-layer combinations for fire protection with much bigger ease allowances added. This was expected since most of the studies do not report the measurements for three-layered ensembles.

The results listed in Table 4 also point to much bigger values of the microclimatic air volume than previously reported by any other studies [24, 27].

There was a small difference in the calculated volume $\left(\mathrm{V}_{\mathrm{CE}}\right)$ and the area $\left(A_{C E}\right)$ between the clothing ensembles CE 2, CE 3, and CE 4. This is due to fabric folding and overlapping, regardless of the actual ease allowance value added to the jacket construction [20]. Fabric drape of the textile materials is directly related to the sense of fullness and graceful appearance of a garment during wear [72]. Loose-fitting clothing provides a larger surface area as well as a greater clothing microenvironment volume [73], but provides more draping. When compared to the area of the pattern parts as summarized in Table 2, there is a distinguished difference between the area of the scanned jackets and the area of the two-dimensional (2D) patterns. This difference is the consequence of overlapping and wrinkling of the fabric when the garments are worn over the body.

Since previous studies verified the strong influence of wind and human moving on the thermal insulation value of clothing, the insulation values were compared between static (thermal manikin standing) and dynamic conditions (thermal manikin moving).

The average total and effective insulation values, together with the calculated variance $\left(\mathrm{s}^{2}\right)$, for the selected clothing garments, are summarized in Table 5. The maximum thermal insulation with the thermal manikin stationary was measured for jacket's microclimatic volume of $13.56 \mathrm{dm}^{3}$ [31].

Table 3. Calculation of the overall ensemble volume $\left(V_{C E}\right)$, the overall ensemble area $\left(A_{C E}\right)$ using the Reverse Engineering software Geomagic Verify Viewer together with calculated average $(\overline{\mathrm{X}})$ and standard deviation (s) values

\begin{tabular}{|c|c|c|c|}
\hline Scanned object & Statistics & $\mathbf{V}_{\mathrm{CE}}\left(\mathrm{dm}^{3}\right)$ & $A_{C E}\left(m^{2}\right)$ \\
\hline \multirow{2}{*}{ Naked body } & $\overline{\mathrm{X}}$ & 78.58 & 1.95 \\
\hline & s & 0.0205 & 0.0094 \\
\hline \multirow{2}{*}{ Body dressed in CE 0 (no jacket is added as outer garment) } & $\overline{\mathrm{x}}$ & 97.83 & 2.26 \\
\hline & s & 0.0544 & 0.0125 \\
\hline \multirow{2}{*}{ Body dressed in CE 1 (jacket variant CG 1 added as outer garment) } & $\overline{\mathrm{x}}$ & 109.34 & 2.32 \\
\hline & $\mathrm{s}$ & 0.0321 & 0.0102 \\
\hline \multirow{2}{*}{ Body dressed in CE 2 (jacket variant CG 2 added as outer garment) } & $\overline{\mathrm{X}}$ & 111.39 & 2.36 \\
\hline & s & 0.0267 & 0.0055 \\
\hline \multirow{2}{*}{ Body dressed in CE 3 (jacket variant CG 3 added as outer garment) } & $\overline{\mathrm{x}}$ & 112.15 & 2.40 \\
\hline & $\mathrm{s}$ & 0.0163 & 0.0125 \\
\hline \multirow{2}{*}{ Body dressed in CE 4 (jacket variant CG 4 added as outer garment) } & $\overline{\mathrm{x}}$ & 112.69 & 2.43 \\
\hline & $\mathrm{s}$ & 0.0090 & 0.0060 \\
\hline
\end{tabular}


Table 4. Calculation of the microclimatic air volume for the selected jackets $\left(\mathrm{V}_{\mathrm{MLCG}}\right)$ and clothing ensembles $\left(\mathrm{V}_{\mathrm{ML}, \mathrm{CE}}\right)$ using the Reverse Engineering software Geomagic Verify Viewer together with calculated average $(\overline{\mathrm{X}})$ and standard deviation (s) values

\begin{tabular}{|c|c|c|c|c|}
\hline Jacket variant & Increase in ease allowance (\%) & $\mathbf{V}_{\mathrm{ML}, \mathrm{CG}}\left(\mathbf{d m}^{3}\right)$ & Clothing ensemble & $\mathbf{V}_{\mathrm{ML}, \mathrm{CE}}\left(\mathbf{d m}^{3}\right)$ \\
\hline- & - & - & CE 0 & 19.25 \\
\hline CG 1 & - & 11.51 & CE 1 & 30.76 \\
\hline CG 2 & 18.2 & 13.56 & CE 2 & 32.81 \\
\hline CG 3 & 54.6 & 14.32 & CE 3 & 33.57 \\
\hline CG 4 & 72.7 & 14.86 & CE 4 & 34.11 \\
\hline
\end{tabular}

Table 5. Calculation of the average total and effective insulation value for the selected clothing garments together with the calculated variance $\left(\mathrm{s}^{2}\right)$

\begin{tabular}{|c|c|c|c|}
\hline Jacket variant & $\overline{\mathrm{I}}_{\mathrm{t}}$ & $\overline{\mathrm{I}_{\text {clu }}}$ & $\mathbf{s}^{2}$ \\
\hline CG 1 & 0.1472 & 0.0728 & $5.05 \times 10^{-05}$ \\
\hline CG 2 & 0.1569 & 0.0826 & $7.66 \times 10^{-05}$ \\
\hline CG 3 & 0.1561 & 0.0817 & $4.80 \times 10^{-05}$ \\
\hline CG 4 & 0.1510 & 0.0766 & $1.93 \times 10^{-05}$ \\
\hline
\end{tabular}

The average total and effective insulation values, together with the calculated variance $\left(\mathrm{s}^{2}\right)$, for the selected clothing ensembles are summarized in Table 6. For ensembles' microclimatic volumes up to $33.57 \mathrm{dm}^{3}$ in static [31] and up to $30.76 \mathrm{dm}^{3}$ in dynamic conditions, the insulation enlargement was measured as summarized in Table 6 . There was an obvious change in the insulation value due to the effects of walking.

For microclimatic volume of $33.57 \mathrm{dm}^{3}$ formed under ensembles with corresponding $14.32 \mathrm{dm}^{3}$ of air volume formed under jacket, the maximum thermal insulation in static conditions was measured [31]. For dynamic conditions, the maximum insulation was measured for ensemble's microclimatic volume of $30.76 \mathrm{dm}^{3}$ (with $11.51 \mathrm{dm}^{3}$ of air volume under jacket). The jacket with smallest microclimatic volume provided $5.2-13.5 \%$ less insulation than wider jackets with larger microclimatic volume.

The ensembles' insulation ranged $0.0938<\mathrm{I}_{\text {cle }}<0.0956$ and $0.0754<I_{\text {cler }}<0.0775$, thus pointing to conclusion that subjects will start to feel discomfort during rest when exposed to lower ambient temperatures $\left(10^{\circ} \mathrm{C}\right.$ and $\left.15^{\circ} \mathrm{C}\right)$.

The ensembles with tighter jackets added as the outerwear garments showed $0.74-1.9 \%$ less insulation in static conditions [31] and $0.9-2.7 \%$ more insulation in dynamic conditions. The ensembles' insulation increased by $49.6-52.4 \%$ with jacket added on top of underlying garments in static conditions and by $27.6-31.1 \%$ in dynamic conditions. There was a significant fall in the effective thermal insulation values of the ensembles in static and dynamic conditions.

The increase in the ease allowance value caused simultaneous air volume amplification in the microclimatic area. The percentage of the volume and insulation increase for ensembles was calculated in comparison to nude body as shown in Figure 2.

Between CG 1 and CG 2, there was an increase in the ease allowance for $18.2 \%$, which caused ensemble's microclimatic volume increase by $17.3 \%$ (CE 2) and this volume enlargement accounted for $51.8 \%$ increase in ensemble's insulation value during rest and for $26.45 \%$ insulation increase in dynamic conditions. Additional ease allowance increase in jackets in amount of $36.4 \%$ (between CG 2 and CG 3) caused the overall ensemble's volume enlargement for another $0.97 \%$ (between CE 2 and $C E 3$ ) and the corresponding insulation increase by $1.81 \%$ in static conditions and by $2.28 \%$ in dynamic conditions. Further $18.1 \%$ ease allowance increase between jackets CG 3 and CG 4 caused the overall ensemble's volume increased by $0.69 \%$ (CE 4 ), thus providing ensemble's insulation decrease by $1.7 \%$ in static conditions and $0.24 \%$ insulation decrease in

Table 6. Calculation of the average total and effective insulation value for the selected clothing ensembles together with the calculated variance $\left(\mathrm{s}^{2}\right)$

\begin{tabular}{|c|c|c|c|c|c|c|}
\hline Ensemble variant & $\overline{\mathrm{I}_{\mathrm{t}}}$ & $\overline{\mathrm{I}_{\text {cle }}}$ & $\mathbf{s}^{2}$ & $\overline{\mathrm{I}_{\mathrm{tr}}}$ & $\overline{\mathrm{I}_{\text {cler }}}$ & $\mathbf{s}^{2}$ \\
\hline CE 0 & 0.4042 & 0.0627 & $1.25 \times 10^{-04}$ & 0.3814 & 0.0591 & $3.69 \times 10^{-05}$ \\
\hline CE 1 & 0.6052 & 0.0938 & $2.01 \times 10^{-04}$ & 0.5002 & 0.0775 & $7.97 \times 10^{-05}$ \\
\hline CE 2 & 0.6094 & 0.0945 & $2.79 \times 10^{-04}$ & 0.4862 & 0.0754 & $1.27 \times 10^{-04}$ \\
\hline CE 3 & 0.6165 & 0.0956 & $2.50 \times 10^{-04}$ & 0.4953 & 0.0768 & $5.66 \times 10^{-05}$ \\
\hline CE 4 & 0.6100 & 0.0945 & $3.67 \times 10^{-04}$ & 0.4943 & 0.0766 & $5.21 \times 10^{-05}$ \\
\hline
\end{tabular}




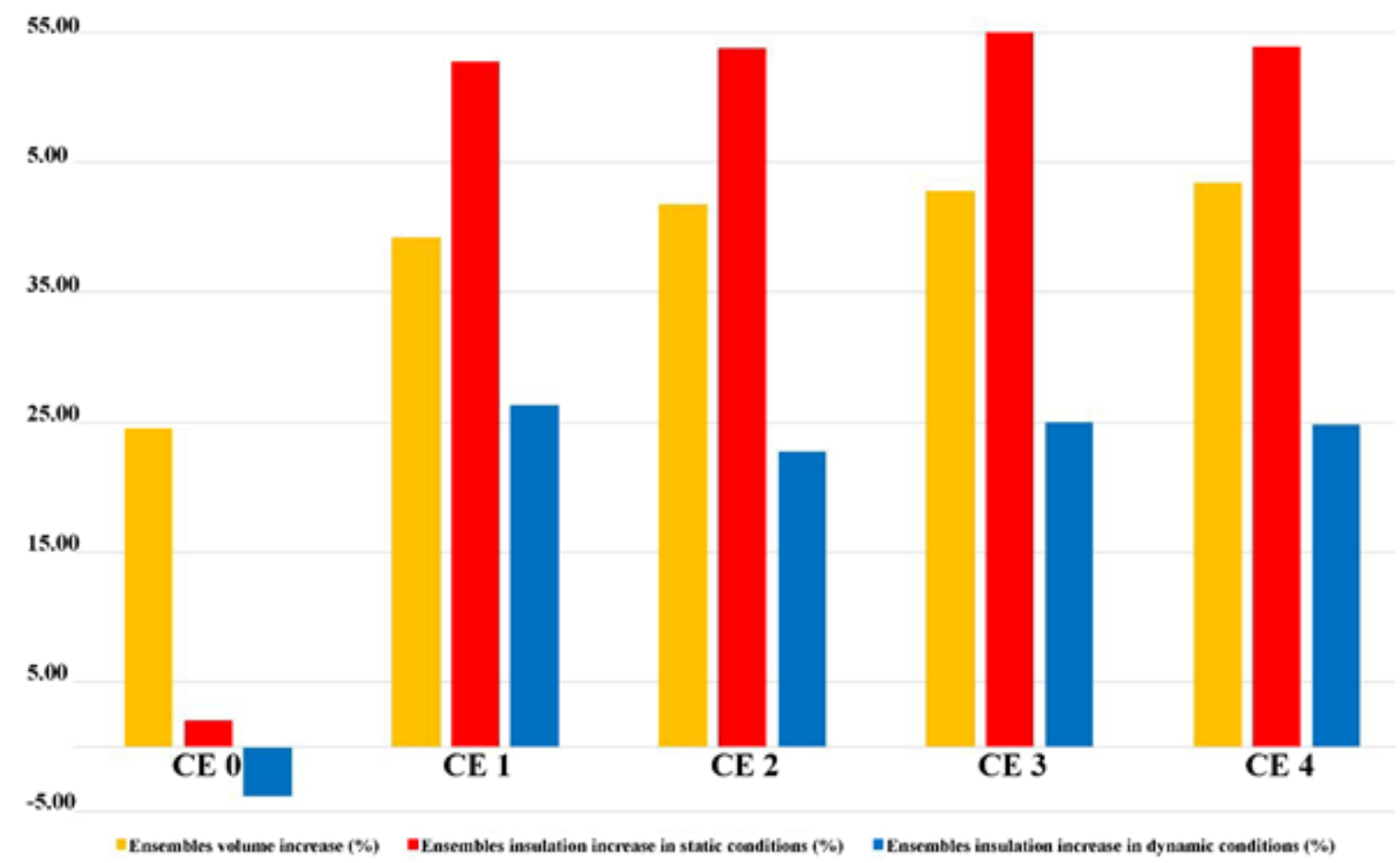

Figure 2. The percentage of the increase for the microclimatic volume and the effective thermal insulation of the ensembles

dynamic conditions. In other words, the enlargement of the microclimatic volume causes the insulation increase in both jackets and ensembles up to a certain critical point. It also causes corresponding ensembles' insulation decrease with the thermal manikin moving.

The correlation analysis showed moderate positive linear relationship between the volume of ensembles to effective thermal insulation measured at static conditions $(r=0.7)$ but weak negative linear relationship to effective thermal insulation measured at dynamic conditions $(r=-0.44)$.

The effective thermal insulation value was reduced by $20.98 \%$ between the standing and moving manikins for CE 1 . For CE 2, the reduction in the effective thermal insulation in dynamic conditions in comparison to the static conditions was $25.34 \%$. The overall reduction in insulation value decreased from $25.34 \%$ to $24.48 \%$ for CE 3 , and even further insulation reduction to $23.41 \%$ was shown for CE 4 .

If the main intention is to provide the smaller reduction in the effective thermal insulation value during activities, increase in the ease allowance of the outerwear clothing should be either smaller than $47 \%$ or bigger than $153 \%$ if we presume the value of ease allowance in amount of $15 \mathrm{~cm}$ to be the reference point. The highest effective thermal insulation value was observed for the jacket's ease allowance value of $34 \mathrm{~cm}$ with thermal manikin stationary. However, in dynamic conditions, with the thermal manikin moving, the highest effective thermal insulation value was recorded for jacket with $22 \mathrm{~cm}$ of the ease allowance added. The smaller the increase in the ease allowance value, the smaller the reduction in the effective thermal insulation in dynamic conditions.

\subsection{Wear trials: the subjects' physiological data and grade analysis}

The physiological data, recorded simultaneously during the wear trials in controlled simulated laboratory environments, are important mean by which the ergonomist can control whether or not the subjects feel comfortable during testing. They also test the influence the different human sensations on the overall thermal comfort perception under different activity levels and different environment conditions. In this section, the mean temperature and the $\mathrm{RH}$ of skin are analyzed. The secreted sweat was also calculated in order to see the average body mass loss and sweat accumulation into clothing during actual clothing usage. The average mean skin temperature and $\mathrm{RH}$ were calculated for each climatic condition, worn ensemble, and trial phase separately.

The average mean skin's temperature values $\left(\mathrm{t}_{\mathrm{sk}}\left[{ }^{\circ} \mathrm{C}\right]\right)$ for each subject's dresses in selected clothing ensembles are shown in Figure 3 during all trial phases in different climatic conditions. In the climatic condition $\mathrm{A}$ with the highest ambient temperature of $20^{\circ} \mathrm{C}$, the average value of the mean skin temperature at rest was $32.10^{\circ} \mathrm{C}$, at first walking phase was $32.25^{\circ} \mathrm{C}$ and $31.84^{\circ} \mathrm{C}$ at second walking phase. With the drop of the ambient temperature for $5^{\circ}$ in the climatic condition $\mathrm{B}$, the average mean skin values decreased for about $0.91^{\circ}$ in the first phase, for about $1.23^{\circ}$ in the second and 1.67 in the third phase. With further drop of the ambient temperature for another $5^{\circ}$, the mean skin temperature in the first phase decreased for about $0.31^{\circ}$, for about $0.57^{\circ}$ in the second and 0.85 in the third phase. The mean skin temperature generally ranged from minimum $28.52^{\circ} \mathrm{C}$ to maximum $33.65^{\circ} \mathrm{C}$ in the climatic condition $\mathrm{C}$, from 
$29.03^{\circ} \mathrm{C}$ to $34.09^{\circ} \mathrm{C}$ in the climatic condition $\mathrm{B}$, and from 29.61 to $33.30^{\circ} \mathrm{C}$ in the climatic condition $\mathrm{A}$.

Since the mean skin value of $30-32^{\circ} \mathrm{C}$ is considered comfortable, pointing to conclusion that subjects are exposed to neutral comfort zone. This also points to conclusion that the perceptual adaptation was fully achieved at ambient temperature of $20^{\circ} \mathrm{C}$. When the mean skin temperatures falls below $31^{\circ} \mathrm{C}$, discomfort occurs [64] as seen with temperature decrease in phases 2 and 3 at ambient temperature of $15^{\circ} \mathrm{C}$ and through all phases at ambient temperature of $10^{\circ} \mathrm{C}$.
Generally, the highest mean skin temperature values were recorded for $\mathrm{CE} 4$ at the climatic condition A during all three phases. In the climatic conditions $B$ and $C$, the highest recorded values of the mean skin temperature were while wearing $C E$ 1. Generally, conditions, the highest mean skin temperatures, were recorded at the first walking phase during all climatic conditions.

The recorded values of the skin's $\mathrm{RH}$ are presented in Figure 4. The highest values of $\mathrm{RH}$ were recorded for the climatic condition A, especially at the resting phase while the second

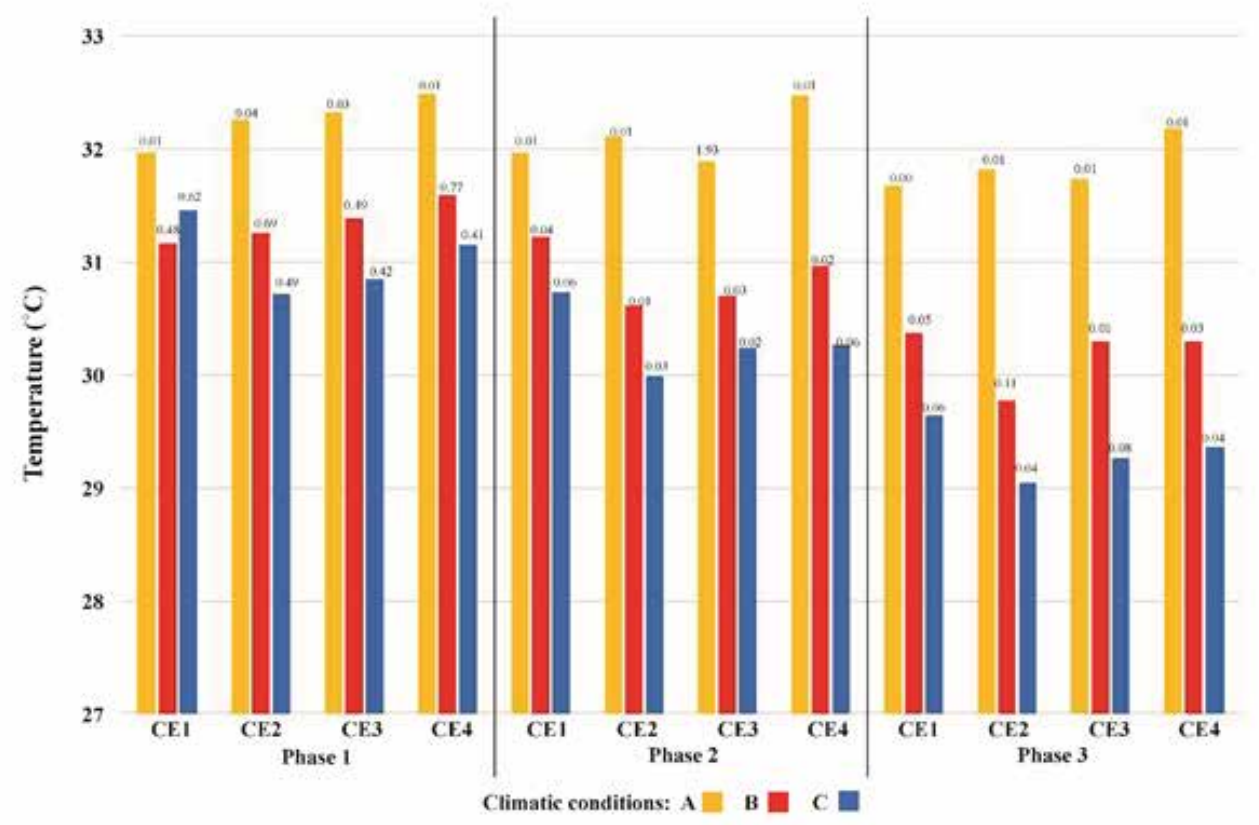

Figure 3. The average mean skin's temperature $\left(t_{s k}\left[{ }^{\circ} \mathrm{C}\right]\right)$ and variances $\left(s^{2}\right)$ for each ensemble during all trial phases in different climatic conditions

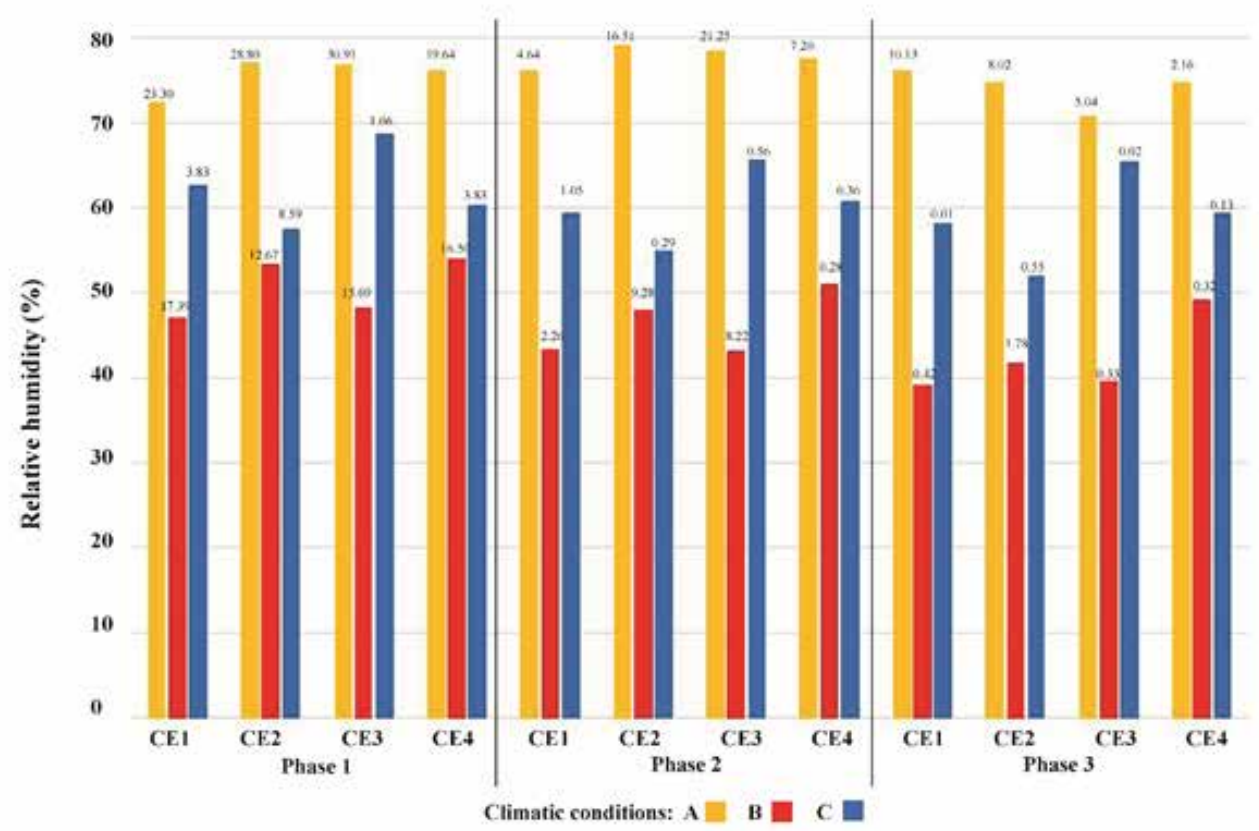

Figure 4. The average skin's relative humidity $\left(\mathrm{RH}_{\mathrm{sk}}[\%]\right)$ and variances $\left(\mathrm{s}^{2}\right)$ for each ensemble during all trial phases in different climatic conditions 
highest values of the humidity were measured in the coldest environment during the first walking phase. Overall, the highest recorded values were shown for $C E 2$ in the climatic condition $A$, for CE 3 in the climatic condition B and CE 4 in the climatic condition $\mathrm{C}$.

In the climatic condition A with the highest ambient temperature of $20^{\circ} \mathrm{C}$, the average value of the skin's $\mathrm{RH}$ at rest was $77.8 \%$, $75.6 \%$ at first walking phase and $74.0 \%$ at second walking phase. With the drop of the ambient temperature for $5^{\circ}$ in the climatic condition $\mathrm{B}$, the average skin's $\mathrm{RH}$ values decreased for about $22.1 \%$ in the first phase, for about $26.4 \%$ in the second and $31.6 \%$ in the third phase. With further drop of the ambient temperature for another $5^{\circ}$, the skin's $\mathrm{RH}$ started increasing for about $11.7 \%$ in the first walking phase, for about $13.8 \%$ in the second and $16.3 \%$ in the third phase.

The values of the body mass loss due to sweating were also calculated (Figure 5), but the measurements were taken after each trial, so the values were not given for each phase separately. The highest values of the body mass loss due to sweating were calculated for CE 4 in the climatic conditions A (203.6 g) and C (188.9 g) as expected since the measured values of the mean skin temperature and $\mathrm{RH}$ were also high.

The garment's weight was measured before subjects entered climatic chamber and after they completed trials. The average difference in total ensemble's weight points to sweat accumulation into clothing which is particularly pronounced at lower ambient temperatures as shown in Figure 5. Under coolest climatic conditions, the skin's RH increased, causing subjects to accumulate sweat into their clothing, especially while wearing tighter jackets.

The subjects filling-in questionnaires expressed no or little dissatisfaction with the environmental conditions or the clothing. The grades leaning toward discomfort were shown for the lowest ambient temperature at resting phase although the subjects stated that the thermal environment is generally acceptable considering the grades given to question 3 . The grades are in the range of the thermal neutrality. The slight discomfort was determined only for the clothing ensembles CE 1 and CE 3 (Figure 6).

Generally, the highest grades were given while wearing CE 4 (the outerwear was jacket with the highest value of the ease allowance and consequently the greatest volume of the microclimatic air layer inside the ensembles). The lowest grades were displayed for CE 1 and 3 . When sweat starts to condense into clothing, it will cause the subjects to feel uncomfortable.

The subjects exposed to lower ambient temperatures (the ambient conditions $\mathrm{B}$ and $\mathrm{C}$ ) gave lower grades to the ensembles with the tighter jackets. Although CE 4 did not have the highest value of the effective thermal insulation in the dynamic conditions, it was judged as the best clothing ensemble by the subjects in the climatic conditions $C\left(t_{a}=10^{\circ} \mathrm{C}\right)$.

The percentage of judgments expressing discomfort was calculated for the questions 1,2 , and 3 . The highest percentage of judgments expressing discomfort was given under the climatic conditions $B$ and $C$ in the resting phase (phase 2) for all of the

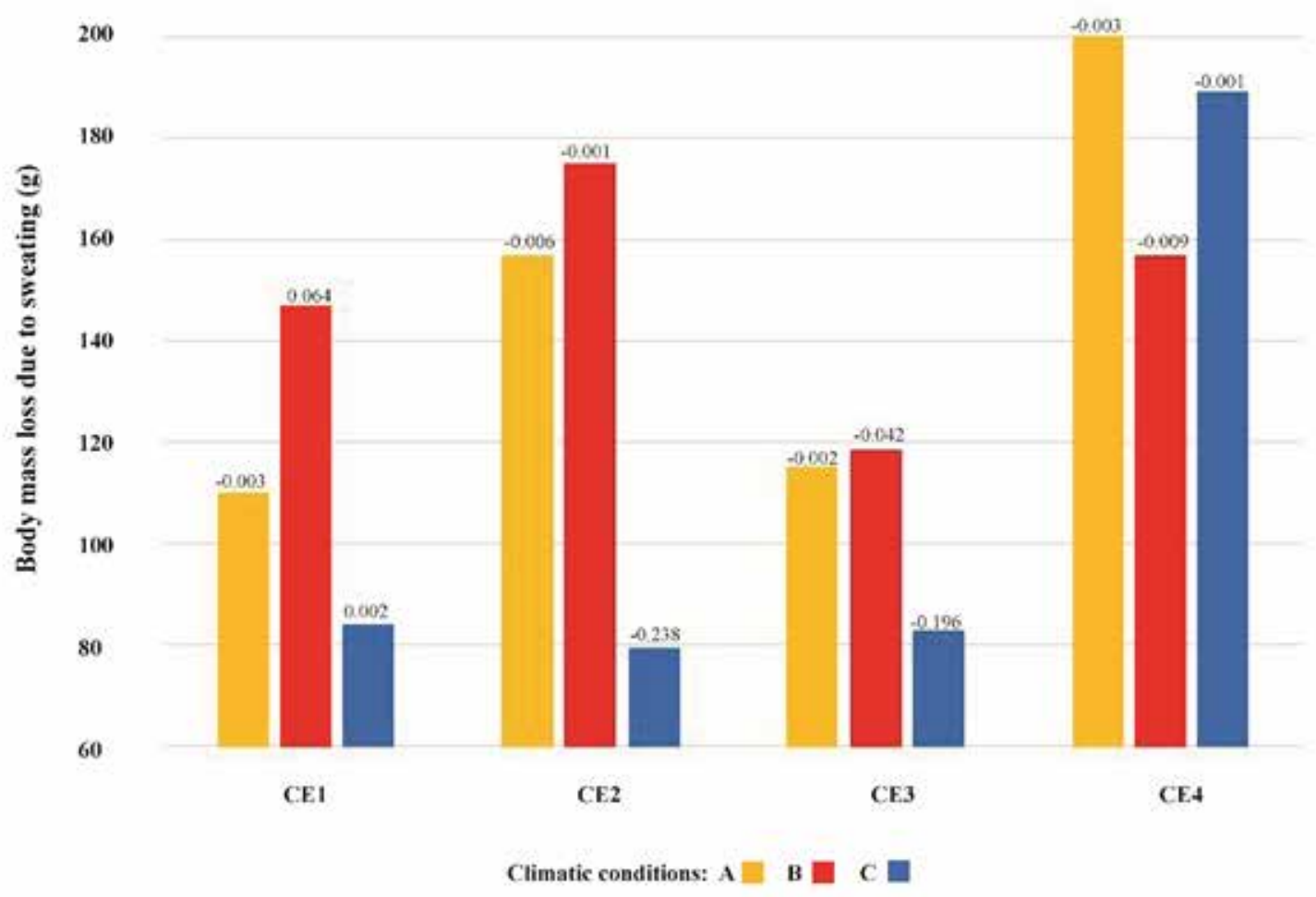

Figure 5. Calculation of the average body mass loss due to sweating $\left(\Delta \mathrm{m}_{\mathrm{sw}}\right)$ with the average difference in ensemble's weight $\left(\Delta \mathrm{m} \mathrm{cl}_{\mathrm{l}}\right)$ shown as numeric value for the selected clothing ensembles 
questions, especially for CE 1 and CE 2. There was almost no or negligible percentage of dissatisfied subjects in the first walking phase under all environmental conditions except while wearing CE 3 under the condition $\mathrm{C}$. In the third walking phase, the highest percentage of judgments expressing discomfort was found for CE 1 and CE 3 under the condition C (Figure
6). The highest percentage of the comfort was given for CE 4 throughout all the climatic conditions. As previously reported, discomfort occurs when the mean skin temperature falls below $31^{\circ} \mathrm{C}$. Decrease in the mean skin temperature below that value was accompanied with a higher percentage of judgments expressing discomfort during exposures to cool environments.
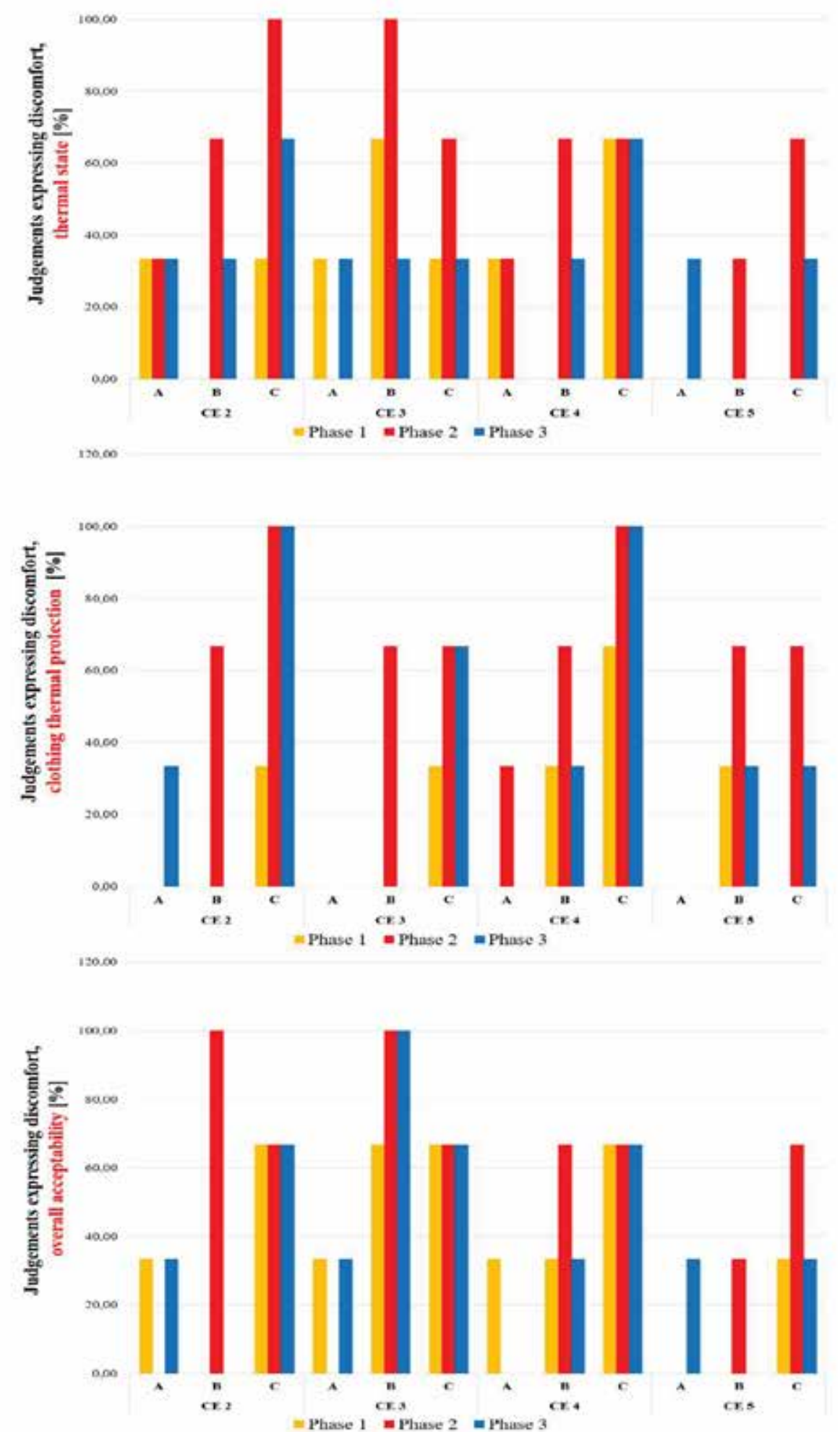

Figure 6. The percentage of judgments expressing discomfort with the thermal state (question 1), the thermal protection provided by the clothing (question 2), and the overall acceptability (question 3) 
The percentage of judgments expressing discomfort with the thermal state negatively correlates with ensemble's volume through all phases of trials and all climatic conditions. Strong negative linear relationship was proven during resting phase at $t_{a}=10^{\circ} \mathrm{C}(r=-0.9)$. Moderate linear relationship during resting phase at $\mathrm{t}_{\mathrm{a}}=10^{\circ} \mathrm{C}$ was also proven to effective thermal insulation measured at static (-0.7) and dynamic conditions (0.8).

Since Li's study [24] pointed to the relation between the comfort perception to skin a temperature and microclimate $\mathrm{RH}$ during environmental transients, the multiple regression analysis was performed. It showed that $42.43 \%$ of the variation to the percentage of judgments expressing discomfort $\left(D_{e x}[\%]\right)$ with the clothing thermal protection is explained by the variation of the skin's $\left(\mathrm{RH}_{\mathrm{sk}}[\%]\right)$ and the mean skin temperature $\left(\mathrm{t}_{\mathrm{sk}}\left[{ }^{\circ} \mathrm{C}\right]\right)$ :

Dex $=850.5+0.46 \mathrm{RH}_{\mathrm{sk}}-27.2 \mathrm{t}_{\mathrm{sk}}$

multiple $R=0.65 ; R^{2}=0.4243 ; p=1.1 \times 10^{4} ; S=27.5$

In order to compare the results and to examine the relationship between several independent and criterion variables, the multiple regression analysis has been performed. The criterion variable was the percentage of judgments expressing discomfort $\left(\mathrm{D}_{\mathrm{ex}}[\%]\right)$. Since the multiple regression can be used to find relationship between variables, the comparison was performed to the measured values of the microclimatic volume $\left(V_{\mathrm{ml}}\left[\mathrm{dm}^{3}\right]\right)$, the effective thermal insulation of clothing ensemble in static conditions $\left(I_{\text {cle }}\left[\mathrm{m}^{2} \mathrm{~K} / \mathrm{W}\right]\right)$, and the effective thermal insulation of clothing ensemble in dynamic conditions $\left(I_{\text {cler }}\left[m^{2} \mathrm{~K} / \mathrm{W}\right]\right)$.

From Table 8, the observed F-test statistics for all comparisons has the $p$-value (significant $F$ ) greater than 0.05 , except in the case of climatic condition A when comparing the percentage of judgments expressing discomfort to the measured values of the microclimatic volume and the effective thermal insulation of clothing ensemble in static conditions. Since the p-value is not less than 0.05 , we do not reject the null hypothesis that the regression parameters are zero at significance level 0.05 . We reject the null hypothesis only in the abovementioned example and can conclude that the regression parameters are not zero at significance level 0.05 .

When observing the computed $p$-values of the regression parameters as summarized in Table 8 , one can conclude that the parameters are jointly statistically insignificant at the significance level of 0.05 for most of the comparisons, although the percentage of the mutual influences are high. Only in the case of the climatic condition A, when comparing the values of the percentage of judgments expressing discomfort to the measured values of the microclimatic volume and the effective thermal insulation of clothing ensemble in static conditions, the observed coefficient of $\mathrm{V}_{\mathrm{ml}}$ has estimated the standard error of 0.38 , t-statistic of -21.0435 , and p-value of 0.03 . It is therefore statistically significant at significance level $a=0.05$ as $p<0.05$.

The multiple regression of the ensemble's microclimatic volume $\left(V_{m l}\left[\mathrm{dm}^{3}\right]\right)$ to the effective thermal insulation of clothing ensemble in static conditions $\left.\left(\mathrm{I}_{\text {cle }}\left[\mathrm{m}^{2} \mathrm{~K} / \mathrm{W}\right]\right)\right)$ and the percentage of judgments expressing discomfort $\left(\mathrm{D}_{\mathrm{ex}}[\%]\right)$ shows that $99.8 \%$ of the variation of $D_{e x}$ is explained by the regression of $V_{m l}$ and $\mathrm{I}_{\text {cle }}$ only for climatic condition A.

$$
D_{e x}=-297.13-7.9 V_{m l}+6115.2 I_{c l e}
$$

The observed results point to conclusion that this preliminary study should be further expanded involving more subjects to analyze the impact of the microclimatic air volume formed under the ensembles to the subjective judgments expressed by the subjects on the thermal comfort felt during wear trials and thermal insulation decrease due to movements.

\section{Conclusions}

The aim of this study is to present the preliminary data on the impact of the microclimatic volume expansion under outerwear garments on the overall ensemble's thermal insulation and human satisfaction under walking. The previous studies covering the three-layered ensembles were not reported; thus, this study covered the ensembles accompanied by jackets of different fit, as the outerwear garments, to investigate the impact of the microclimatic volume on the ensembles' thermal insulation. It came to light that additional air volume created by the outerwear does indeed dominates the overall ensembles' thermal properties, especially during walking.

The impact of the microclimatic air volume on the overall insulation value was tested under dynamic condition. The insulation decrease under dynamic conditions proved that the impact of the air currents and ventilation of the air inside the

Table 7. Multiple regression summary

\begin{tabular}{|c|c|c|c|c|c|c|}
\hline Climatic condition & A & B & C & A & B & C \\
\hline Comparing $\mathrm{D}_{\mathrm{ex}}$ to & $\mathrm{I}_{\text {cler }}$ and $\mathrm{V}_{\mathrm{ml}}$ & $\mathrm{I}_{\text {cler }}$ and $\mathrm{V}_{\mathrm{ml}}$ & $\mathrm{I}_{\text {cler }}$ and $\mathrm{V}_{\mathrm{ml}}$ & $\mathrm{I}_{\text {cle }}$ and $\mathrm{V}_{\mathrm{ml}}$ & $\mathrm{I}_{\text {cle }}$ and $\mathrm{V}_{\mathrm{ml}}$ & $\mathrm{I}_{\text {cle }}$ and $\mathrm{V}_{\mathrm{ml}}$ \\
\hline Multiple $\mathrm{R}$ & 0.93 & 0.92 & 0.69 & 0.99 & 0.38 & 0.97 \\
\hline $\mathrm{R}^{2}$ & 0.8674 & 0.8522 & 0.4730 & 0.9981 & 0.1422 & 0.9420 \\
\hline Adjusted $\mathrm{R}^{2}$ & 0.60 & 0.56 & -0.58 & 0.99 & -1.57 & 0.83 \\
\hline Standard error & 5.72 & 15.25 & 20.96 & 0.69 & 36.75 & 6.95 \\
\hline F-value & 3.27 & 2.88 & 0.45 & 259.8 & 0.08 & 8.12 \\
\hline Significant F & 0.36 & 0.38 & 0.73 & 0.04 & 0.93 & 0.24 \\
\hline
\end{tabular}


Table 8. Summary of multiple regression parameters

\begin{tabular}{|c|c|c|c|c|}
\hline & Coefficients & $\begin{array}{c}\text { Estimated standard } \\
\text { deviation }\end{array}$ & t-statistic & p-value \\
\hline \multicolumn{5}{|c|}{ Climatic condition A } \\
\hline Intercept & 198.89 & 366.25 & 0.54 & 0.68 \\
\hline $\mathrm{V}_{\mathrm{ml}}$ & -5.72 & 2.50 & -2.28 & 0.26 \\
\hline $\mathrm{I}_{\text {cler }}$ & 141.82 & 4212.36 & 0.03 & 0.99 \\
\hline \multicolumn{5}{|c|}{ Climatic condition B } \\
\hline Intercept & 2365.88 & 976.39 & 2.42308 & 0.25 \\
\hline $\mathrm{V}_{\mathrm{ml}}$ & -11.18 & 6.68 & -1.6738 & 0.34 \\
\hline $\mathrm{I}_{\text {cler }}$ & -25635.51 & 11229.89 & -2.28279 & 0.26 \\
\hline \multicolumn{5}{|c|}{ Climatic condition C } \\
\hline Intercept & -373.57 & 1341.55 & -0.27846 & 0.83 \\
\hline $\mathrm{V}_{\mathrm{ml}}$ & -4.69 & 9.17 & -0.51151 & 0.69 \\
\hline$I_{\text {cler }}$ & 7578.55 & 15429.76 & 0.491165 & 0.71 \\
\hline \multicolumn{5}{|c|}{ Climatic condition A } \\
\hline Intercept & -297.13 & 62.20 & -4.77673 & 0.13 \\
\hline $\mathrm{V}_{\mathrm{ml}}$ & -7.89 & 0.38 & -21.0435 & 0.03 \\
\hline $\mathrm{I}_{\text {cle }}$ & 6115.20 & 740.96 & 8.25308 & 0.08 \\
\hline \multicolumn{5}{|c|}{ Climatic condition B } \\
\hline Intercept & -686.50 & 3319.64 & -0.21 & 0.87 \\
\hline $\mathrm{V}_{\mathrm{ml}}$ & -8.14 & 20.03 & -0.41 & 0.75 \\
\hline $\mathrm{I}_{\text {cle }}$ & 10462.04 & 39543.32 & 0.26 & 0.84 \\
\hline \multicolumn{5}{|c|}{ Climatic condition $\mathrm{C}$} \\
\hline Intercept & -1721.02 & 627.97 & -2.74 & 0.22 \\
\hline $\mathrm{V}_{\mathrm{ml}}$ & -15.0906 & 3.79 & -3.98 & 0.16 \\
\hline $\mathrm{I}_{\text {cle }}$ & 23984.72 & 7480.34 & 3.21 & 0.19 \\
\hline
\end{tabular}

clothing microclimate is much bigger under greater values of the microclimatic air layers. The prediction is that the observed insulation decrease is due to pronounced bellows effect set to motion during walking, especially with greater microclimatic volumes.

Thermal insulation of the ensembles increased by $49.6-52.4 \%$ with the jacket added as the outerwear garment in static conditions and by $27.6-31.1 \%$ in dynamic conditions. The overall ensembles insulation reduction in dynamic conditions ranged from $21 \%$ to $25 \%$, affirming that the loose-fitting ensembles entrap more air thus showing the larger effect of the movement when compared to the tight-fitting ensembles [12]. The thermal insulation decreased significantly due to walking, which was more pronounced with higher values of the microclimatic air layers trapped inside the jacket's microclimate.
The smaller the increase in the jacket's microclimatic volume provides the smaller the reduction in the effective thermal insulation in dynamic conditions. However, the jacket with the smallest microclimatic volume provided $5.2-13.5 \%$ less insulation than wider jackets with larger microclimatic volume. In general, the ensembles with tighter jackets showed 0.74 $1.9 \%$ less insulation in static conditions [31] and $0.9-2.7 \%$ more insulation in dynamic conditions. The percentage of judgments expressing discomfort with the thermal state negatively correlates with ensemble's volume through all phases of trials and all climatic conditions pointing to conclusion that the comfort state of subjects was greatly influenced with the jacket's fit. It also points that measured thermal insulation values are not high enough to provide adequate thermal protection during resting phases and lower ambient temperatures. 
This paper verified that the increase in the ease allowance, and simultaneously the size of an air gap quantified as overall microclimatic volume, induces increase in the effective thermal insulation value up to a certain threshold volume. The main novelty of the study is that the microclimatic volume value, after which the thermal insulation begins to decrease as a result of convection, is greater than previously reported by other authors. The limiting value is greater than previously reported by Li et al. [24] and Zhang and Li [27], but proved MacRea's report that the outerwear and additional air spaces appear to dominate the overall thermal properties of clothing ensembles (2011).

The ensembles' insulation enlargement was measured for microclimatic volumes up to $33.57 \mathrm{dm}^{3}$ in static [31] and up to $30.76 \mathrm{dm}^{3}$ (volume of $11.51 \mathrm{dm}^{3}$ ) in dynamic conditions. Although the ensemble with tighter jacket had the highest measured insulation, subjects declared greater discomfort in colder environments. It points to conclusion that the persons deduce their satisfaction on both the clothing's insulation and wearing comfort. However, evidence is lacking for other types of outerwear garments and more research is needed. Future research should investigate larger selection of outerwear models, subjects, and body postures to provide better understanding on the impact of the microclimatic volume formed under the outerwear garments and the impact on human thermal comfort.

\section{Acknowledgments}

This work is a part of a PhD work of the first author. On behalf of all the authors, the corresponding author states that there is no conflict of interest.

\section{Competing interests}

The authors declare that they have no competing interests.

\section{References}

[1] Taya, Y., Ohno, S., Mihira, K. (1982). Measurements of the clothing microclimate volumes (part I) - a method of measurement of clothing microclimate volumes and its evaluation. Journal of Home Economics of Japan, 33(7), 374-379, DOI:10.11428/jhej1951.33.374.

[2] Parkova, I., Vilumsone, A. (2011). Microclimate of smart garment. Scientific Journal of Riga Technical University, 6, 99-103

[3] Özdemir, H. (2017). Thermal comfort properties of clothing fabrics woven with polyester/cotton blend yarns. AUTEX Research Journal, 17(12), 135-141

[4] Daanen, H., Hatcher, K., Havenith, G. (2002). Determination of clothing microclimate volume. In: Proceedings of the 10th International Conference on Environmental Ergonomics. Tochihara, Y., Ohnaka. T. (Ed.). Kyushu Institute of Design (Fukuoka, Japan), 665-668.

[5] Mert, E., Böhnisch, S., Psikuta, A., Bueno, M.-A., Rossi, R. M. (2016). Contribution of garment fit and style to thermal comfort at the lower body. International Journal of Biometeorology, 60(12), 1995-2004, DOI:10.1007/s00484016-1258-0.
[6] McQuerry et al. (2018)

[7] Frackiewicz-Kaczmarek, J., Psikuta, A., Bueno, M.A., Rossi, R. M. (2015). Effect of garment properties on air gap thickness and the contact area distribution. Textile Research Journal, 85(18), 1907-1918. doi:10.1177/0040517514559582.

[8] Frackiewicz-Kaczmarek, J., Psikuta, A., Bueno, M.-A., Rossi, R. M. (2015). Air gap thickness and contact area in undershirts with various moisture contents: influence of garment fit, fabric structure and fiber composition. Textile Research Journal, 85(20), 2196-2207, DOI:10.1177/0040517514551458.

[9] Lee, Y., Hong, K., Hong, S. A. (2007). 3D quantification of microclimate volume in layered clothing for the prediction of clothing insulation. Applied Ergonomics, 38, 349-355.

[10] Spencer-Smith, J. L. (1977). The physical basis of clothing comfort, part 2: Heat transfer through dry clothing assemblies. Clothing Research Journal, 5(1), 3-17.

[11] Nielsen, R., Olesen, B. W., Fanger, P. O. (1985). Effect of physical activity and air velocity on the thermal insulation of clothing. Ergonomics, 28(12): 1617-1631, DOI:10.1080/00140138508963299

[12] Havenith, G., Heus, R., Lotens, W. A. (1990). Resultant clothing insulation: a function of body movement, posture, wind, clothing fit and ensemble thickness. Ergonomics, 33(1), 67-84.

[13] Havenith, G. (2002). The interaction of clothing and thermoregulation, Exogenous Dermatology 1(5): 221-230.

[14] Morrissey, M. P., Rossi, R. M. (2013). The effect of wind, body movement and garment adjustments on the effective thermal resistance of clothing with low and high air permeability insulation. Textile Research Journal, 84(6), 583-592, DOI:10.1177/0040517513499431.

[15] Psikuta, A., Mert, E., Annaheim, S., Rossi, R. M. (2018). Local air gap thickness and contact area models for realistic simulation of human thermo-physiological response. International Journal of Biometeorology, 62(7), 1121-1134. doi:10.1007/s00484-018-1515-5.

[16] Clark, R. P., de Calcina-Goff, M. L. (2009). Some aspects of the airborne transmission of infection. Journal of the Royal Society Interface, 6(6), 767-782.

[17] Ersting's Aviation Medicine, Fourth edition. (2006). Rainford, D. J., Gradwell, D.P. (Ed.). Hodder Education (London, UK), ISBN 978-0-340-81319-5.

[18] Havenith, G. (2005). Clothing heat exchange models for research and application. In: Proceedings of 11th International Conference on Environmental Ergonomics. Holmer, I., Kuklane, K., Gao, C. (Ed.). Lund University (Ystad, Sweden), 66-73.

[19] International Encyclopaedia of Ergonomics and Human Factors, Volume 1, 2nd edition. (2006). Karwowski, W. (Ed.). CRC Press, Taylor \& Francis Group (Florida, USA), ISBN 978-0-415-30430-6.

[20] Mert, E., Psikuta, A., Bueno, M.-A., Rossi, R. M. (2015). Effect of heterogenous and homogenous air gaps on dry heat loss through the garment. International Journal of Biometeorology, 59, 1701-1710, DOI: 10.1007/s00484015-0978- $x$.

[21] Studies in Environmental Science 10: Bioengineering, thermal physiology and comfort. (1981). Cena, K., Clark, J.A. (Ed.). Elsevier Scientific Publishing Company (Amsterdam, The Netherlands), ISBN 0-444-99761-X. 
[22] Mert, E., Böhnisch, S., Psikuta, A., Bueno, M. A. (2015). Determination of the air gap thickness underneath the garment for lower body using $3 D$ body scanning. In: Proceedings of the 6th International Conference on 3D Body Scanning Technologies. D’Apuzzo, N. (Ed.). Homometrica Consulting (Lugano, Switzerland), 114-119.

[23] MacRea, B. A., Laing, R. M., Wilson, C. A. (2011). Importance of air spaces when comparing fabric thermal resistance. Textile Research Journal, 81(19), 1962-1965, DOI: $10.1177 / 0040517510395995$.

[24] Li, J., Zhang, Z., Wang, Y. (2013). The relationship between air gap sizes and clothing heat transfer performance. The Journal of the Textile Institute, 104(12), 1327-1336, DOI:1 0.1080/00405000.2013.802080.

[25] Psikuta, A., Frackiewicz-Kaczmarek, J., Frydrych, I., Rossi, R. M. (2012). Quantitative evaluation of air gap thickness and contact area between body and garment. Textile Research Journal, 82(14), 1405-1413, DOI: 10.1177/0040517512436823.

[26] Zhang, Z.-H., Li, J. (2010). The relationship of garment fit and thermal comfort. In: TBIS 2010 - Textile Bioengineering and Informatics Symposium Proceedings. Li, Y., Qui, Y. P., Luo, X. N., Li, J. - S. (Ed.). Textile Bioengineering and Informatics Society Limited (Hong Kong), 1-3, 1333-1337, ISSN 1942 - 3438.

[27] Zhang, Z., Li, Y. (2011). Volume of air gaps under clothing and its related thermal effects. Journal of Fiber Bioengineering \& Informatics, 4(2), 137-144.

[28] Zhang, Z., Li, J., Wang, Y. (2015). Improving garment thermal insulation property by combining two non contact measuring tool. Indian Journal of Fibre and Textile Research, 40, 392-398.

[29] Mert, E., Psikuta, A., Arévalo, M., Charbonnier, C., LuibleBär, C., Bueno, M.-A., Rossi, R. M. (2018). A validation methodology and application of $3 D$ garment simulation software to determine the distribution of air layers in garments during walking. Measurement, 117, 153-164, DOI:10.1016/j.measurement.2017.11.042.

[30] Jussila, K., Kekäläinen, M., Simonen, L., Mäkinen, H. (2015). Determining the optimum size combination of threelayered cold protective clothing in varying wind conditions and walking speeds: thermal manikin and $3 D$ Body Scanner Study. Journal of Fashion Technology \& Textile Engineering, 3(2), DOI:10.4172/2329-9568.1000120.

[31] Špelić, I. (2018). Changes in Ensembles' Thermal Insulation According to Garment's Fit and Length Based on Athletic Figure. Fibers and Polymers 2018, 19(6), 12781287, DOI 10.1007/s12221-018-1074-8

[32] Holmér, I., Gavhed, C. E., Grahn, S., Nilsson, H. O. (1992). Effects of wind and body movements on clothing insulation - measurement with a moveable thermal manikin. In: Proceedings of the 5th international conference on environmental ergonomics. Lotens, W., Havenith, G. (Ed.), TNO-Intstitute of Perception (Soesterberg, The Netherlands), 66-67, ISBN 90-6743-227-X.

[33] Holmér, I., Nilsson, H., Meinander, H. (1996). Evaluation of clothing heat transfer by dry and sweating manikin measurements. In: Performance of protective clothing, fifth volume, ASTM 1237. Johnson, J. S., Mansdorf, S. Z. (Ed.). American Society for Testing and Materials International (Philadelphia, USA).
[34] Holmér, I., Nilsson, H. O., Anttonen, H. (2002). Prediction of wind effects on cold protective clothing. In: RTO HFM Symposium on "Blowing Hot and Cold: Protecting Against Climatic Extremes", RTO/NATO (Neuilly-sur-Seine Cedex, France), ISBN 92-837-1082-7.

[35] Lim, J., Choi, H., Roh, E. K., Yoo, H., Kim, E. (2015). Assessment of airflow and microclimate for the running wear jacket with slits using CFD simulation. Fashion and Textiles, 2 (1), DOI:10.1186/s40691-014-0025-2

[36] Wagner, A., Dorawa, P. (2016). Research on biophysical properties of protective clothing. AUTEX Research Journal, 16(4), 236-240.

[37] ISO 3801:1977 Textiles - Woven fabrics - Determination of mass per unit length and mass per unit area. ISOInternational Organization for Standardization, 1977

[38] ISO 5084:1996 Textiles - Determination of thickness of textiles and textile products. ISO-International Organization for Standardization, 1996

[39] ISO 9237:1995 Textiles - Determination of the permeability of fabrics to air. ISO-International Organization for Standardization, 1995

[40] ISO 11092:1993 Physiological effects - Measurement of thermal and water - vapour resistance under steady state conditions (Sweating guarded - hotplate test). ISOInternational Organization for Standardization, 1993.

[41] Špelić, I. (2016). Impact of construction parameters on thermal properties of clothing. Ph.D. Thesis. University of Zagreb, Faculty of Textile Technology (Zagreb, Croatia)

[42] Stanković, S. B., Popović, D., Poparić, G. B. (2008). Thermal properties of textile fabrics made of natural and regenerated cellulose fibers. Polymer Testing, 27, 41-48

[43] Pan, N., Gibson, P. (Ed.). (2006). Thermal and moisture transport in fibrous material. Woodhead Publishing Ltd. (Cambridge, United Kingdom), ISBN 978-1-84569-057-1.

[44] Amirova, Z. K., Sakulina, O. V. (1985). Izgotovlenie spetsialnoi i sportivnoi odezhdy. Legprombytizdat (Moskva, Russia).

[45] Moll, M. J., Wright, V. (1972). An objective clinical study of chest expansion. Annals of the Rheumatic Diseases, 31(1), 1-8.

[46] Myers-McDevitt, P. J. (2009). Complete guide to size specification and technical design. Fairchild Books (New York, United States of America).

[47] Yoon, S.-H., Lee, J. (2016). Computing the surface area of three-dimensional scanned human data, Symmetry, 8 (67), DOI:10.3390/sym8070067

[48] Zhang, Z. H., Wang, Y., Li, J. (2011). Model for predicting the effect of an air gap on the heat transfer of a clothed human body. Fibres \& Textiles in Eastern Europe, 19(4), 105-110.

[49]ISO 15831:2004 Clothing - Physiological effects Measurement of thermal insulation by means of a thermal manikin. ISO-International Organization for Standardization, 2004.

[50]ISO 13402 - 3:2004 Size designation of Clothes, Part 3: Measurements and intervals, ISO - International Organization for Standardization, 2004.

[51]ISO/TR 10652:1991 Technical report: Standard sizing system for clothes, 1st ed. ISO - International Organization for Standardization, 1991. 
[52] McCullough, E. A. (2009). Evaluation of cold weather clothing using manikins, ch. 11. In: Textiles for cold weather apparel. Woodhead Publishing in Textiles: No. 93. Williams, J.T. (Ed.). Woodhead Publishing Ltd. (Cambridge, United Kingdom), 244-255, ISBN 978-1-84569-411-1.

[53] Lotens, W. A., Havenith, G. (1991). Calculation of clothing insulation and vapour resistance. Ergonomics, 34 (2), 233254, DOI:10.1080/00140139108967309

[54] Li, Y. (2005). Perceptions of temperature, moisture and comfort in clothing during environmental transients. Ergonomics, 48(3), 234-248, DOI:10.1080/001401304200 0327715.

[55] ISO 10551:2001 Ergonomics of the thermal environment - Assessment of the influence of the thermal environment using subjective judgment scales, ISO - International Organization for Standardization, 2001.

[56] Protective Clothing: Managing Thermal Stress. (2014). Woodhead Publishing Series in Textiles: No. 154. (2014). Wang, F., Gao, C. (Ed.). Woodhead Publishing Ltd. (Cambridge, United Kingdom), ISBN 978-1-78242-032-3.

[57]ISO 14058:2004 Protective clothing - Garment for protection against cool environments. ISO-International Organization for Standardization, 2004.

[58] Gavhed, D. (2003). Human response to cold and wind. NR 2003:4. National Institute for Working Life \& authors (Stockholm, Sweden).

[59] ISO 9886:2004 Ergonomics-Evaluation of thermal strain by physiological measurements, ISO-International Organization for Standardization, 2004.

[60] ASHRAE Handbook Fundamentals (SI ed.). Atlanta, United States of America: American Society of Heating, Refrigerating, and Air Conditioning Engineers Inc. (2005). ISBN 1931862702.

[61] Du Bois, D., Du Bois, E.F. (1916). A formula to estimate the approximate surface area if height and weight be known. Archives of Internal Medicine, 17(6), 863-871, DOI:10.1001/archinte.1916.00080130010002.

[62] Niedermann, R., Psikuta, A., Rossi, R. M. (2014). Prediction of body temperature in humans using noninvasive measurement methods. International Journal of Biometeorology. 58(1), 7-15, DOI: 10.1007/s00484-0130687-2.

[63] Boguslawska-Baczek, M., Hes, L. (2013). Effective water vapour permeability of wet wool fabric and blended fabrics. Fibres \& Textiles in Eastern Europe, 21(1), 67-71.

[64] Lotens, W. A. (1988). Comparison of thermal predictive models for clothed humans. ASHRAE Transactions, 91, 1321-1340.
[65] Liz, W., Lian, Z., Deng, Q. (2015). Use of mean skin temperature in evaluation of individual thermal comfort for a person in a sleeping posture under steady thermal environment. Indoor and Built Environment, 24 (4), 489499.

[66] Lenhardt, R., Sessler, D.T. (2006). Estimation of mean body temperature from mean - skin and core temperature. Anesthesiology, 105(6), 1117-1121.

[67] Hes, L., Ursache, M. (2011). Effect of composition of knitted fabrics on their cooling efficiency at simulated sweating. Short Communication. Indian Journal of Fibre \& Textile Research, 36, 281-284.

[68] Ilmarrinen, R., Tammela, E. (1997). Functional cold protective clothing - a combination of many properties. In: Report of 4th seminar on personal protective equipment in Europe. Jurvelius, H. (Ed.). Finnish Institute of Occupational Health (Kittilä, Finland), 137-144.

[69] Lu, Y., Song, G., Li, J. (2014). A novel approach for fit analysis of thermal protective clothing using threedimensional body scanning. Applied Ergonomics, 45(6), 1439e-1446.

[70] Wang, F., Peng, H., Shi, W. (2016). The relationship between air layers and evaporative resistance of male Chinese ethnic clothing. Applied Ergonomics, 56, 194202, DOI:10.1016/j.apergo.2016.04.005.

[71] McQuerry, M., DenHartog, E., Barker, R. (2016). Evaluating turnout composite layering strategies for reducing thermal burden in structural firefighter protective clothing systems. Textile Research Journal, 87(10), 1217-1225, DOI:10.1177/0040517516651101.

[72] Ng, S. F., Hui, C. L., Tam, F. Y. (2002). Analysis of fabric drape and garment drape. Research Journal of Textile and Apparel, 6(2), 65-74, DOI:10.1108/RJTA-06-02-2002-B006

[73] Kakitsuba, N., Michna, H., Mekjavić, I. B. (1987). Clothing surface area as related to body volume and clothing microenvironment volume. Aviation, Space and Environmental Medicine, 58(5), 411-416.

[74] Improving comfort in clothing. (2011). Song, G. (Ed.). Woodhead Publishing Ltd. (Cambridge, United Kingdom), ISBN 9781845695392.

[75] Jhanji, Y., Gupta, D., Kothari, V. K. (2015). Thermophysiological properties of polyester-cotton plated fabrics in relation to fibre linear density and yarn type. Fashion and Textiles, 2(16), DOI:10.1186/s40691-015-0041-x.

[76] Psikuta, A., Frackiewicz-Kaczmarek, J., Mert, E., Bueno, M. A., Rossi, R. M. (2015). Validation of a novel $3 D$ scanning method for determination of the air gap in clothing. Measurement 67, 61-70, DOI:10.1016/j. measurement.2015.02.024. 